\title{
Raising a Child with Autism: A Developmental Perspective on Family Adaptation
}

\author{
Rebecca McStay • David Trembath • Cheryl Dissanayake
}

Published online: 24 January 2015

(C) Springer International Publishing Switzerland 2015

\begin{abstract}
While raising a child with an Autism Spectrum Disorder (ASD) often produces chronic stress and strain in families, positive family outcomes are also evident following an ASD diagnosis. Although the complex and heterogeneous nature of ASD is well documented, a coherent understanding of the apparent differences in family outcomes is lacking. This review focuses on the process of family adaptation, identifying important contextual factors that may influence family experiences through the use of a conceptual model. Due to inconsistencies in research findings to date, the potential risk and protective factors in determining family outcomes remain unclear, with most research only focusing on mothers. Few studies have attempted to understand family processes utilising a conceptual model of family adaptation, accounting for stressors, resources, appraisal, and coping strategies. The role of child age in the adaptation process has also been ignored with investigation of family processes across key developmental periods needed to assist in tailoring supports and services to families in a timely fashion.
\end{abstract}

Keywords Autism $\cdot$ Stress $\cdot$ Adaptation $\cdot$ Autism severity Problem behaviour $\cdot$ Coping

\section{Autism and the Family}

Autism spectrum disorder (ASD) is a neurodevelopmental disorder characterised by social and communication

This article is part of the Topical Collection on Autism Spectrum

R. McStay $\cdot$ C. Dissanayake $(\bowtie)$

Olga Tennison Autism Research Centre, La Trobe University,

Melbourne, VIC 3086, Australia

e-mail: c.dissanayake@latrobe.edu.au

D. Trembath

School of Allied Heath Sciences, Griffith University, Nathan,

QLD 4222, Australia impairments, and stereotyped, repetitive behaviours and interests [1]. Approximately one in 68 children have an ASD [2], highlighting the importance of research investigating the impact of these complex disorders on families and carers. Delays in diagnosis, the inevitable changes in family life, the educational needs, and the often limited community support means that raising a child with an ASD increases the risk for negative family outcomes across childhood and adult life [3-6]. Research has focused predominately on the construct of caregiver 'burden', with numerous studies highlighting the negative impact of raising a child with an ASD on parents, particularly mother's physical and psychological wellbeing [e.g. 7, 8•, 9, 10].

Parents raising children with ASD have been found to report higher levels of parenting stress, depression and anxiety, and increased general life stress than parents raising children with Down syndrome (DS), cerebral palsy (CP), fragile X syndrome (FXS), intellectual disability (ID), cystic fibrosis (CF) or typically developing (TD) children [e.g. 11-17]. More recently, research identifying the positive aspects of raising a child with a disability has increased, with families identifying both positive and negative outcomes associated with raising children with ASD [e.g. 18], and a focus on resilience in family members [e.g. 19, 20]. These findings reflect a growing awareness of the construct of family adaptation.

Family adaptation refers to a phase of change that results from the restructuring of family processes, such as roles or interactions, in an attempt to accommodate to the consequences of stressors and other life strains [21]. It takes into account the protective factors influencing a family's ability to cope with their child's disability, and any subsequent changes in the family unit. Multivariate models have been used to understand the simultaneous impact of risk and protective factors on family adaptation, providing a framework for identifying factors both within and external to the family unit which contribute to family outcomes in the face of major life 
stress [22]. In doing so, these models tend to focus on parental reports of family life, assessing maternal, paternal or the views of both parents on aspects of the family unit. One model, which has used this approach to examine functioning and adaptation in families of children with ASD, is McCubbin and Patterson's [21] Double ABCX model of adaptation (see Fig. 1).

\section{Theoretical Framework}

The Double ABCX model defines the process of adaptation through identification of key risk and protective factors that may influence family functioning over time. Risk factors are considered as variables that increase the likelihood of adverse or negative outcomes in families [23], such as poorer wellbeing and maladaptation. Alternatively, protective factors act to reduce the impact of risk factors on family outcomes, acting as potential buffers to improve wellbeing, restore homeostasis and support successful adaptation [23].

In McCubbin and Patterson's [21] model, stressors (A) are defined as expected or unexpected life events that cause changes in the family system (e.g. diagnosis of a child). In addition to the initial stressor, the model accounts for a pileup of demands (e.g. prior strains and expected transitions within the family unit) that may compound the initial stress experienced by families (aA) [6,21]. Two variables proposed to moderate the impact of stressors on family outcomes are family resources and appraisals. While resources (B) include existing skills and characteristics that the family draw upon to cope with stressors (e.g. the support of individual family members, the family unit, or the community), appraisals (C) consider the family's interpretation and understanding of the stressor and its impact on the family system (e.g. seeing the stressor as a challenge that can be overcome) $[6,21]$. The model also accommodates for expanded resources (bB) obtained over time, as families learn to cope with the stressor, and subsequent changes in definitions and meaning $(\mathrm{cC})$ of the overall crisis situation.

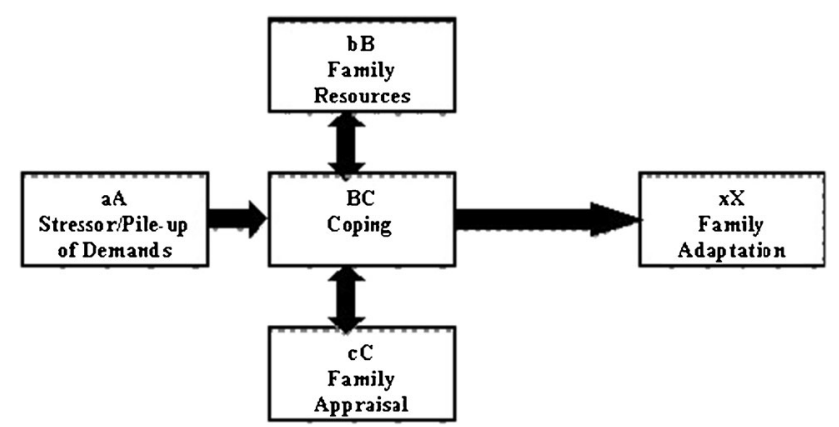

Fig. 1 Double ABCX model of family adaptation. Based on McCubbin and Patterson [21]
In addition to the three variables described, coping (BC) is an important factor that connects family resources and appraisals [6]. Coping is viewed as the ability of family members to seek out and apply resources to manage a stressful event and restore balance within the family unit (e.g. seeking support from the community or one's spiritual beliefs) [21, 24]. Family adaptation $(\mathrm{xX})$ represents the outcome of interactions between the four components of the model. Represented by positive and/or negative outcomes, it symbolises a family's attempt at reaching a new level of homeostasis following upset to the family system [21].

While a number of theoretical models exist for understanding stress and coping in families, including Hill's [25] ABCX family crisis model, Lazarus and Folkman's [26] model of stress and coping, and Luthar and colleagues' [27] resilience theory, the double $\mathrm{ABCX}$ model was chosen for a number of reasons. Firstly, unlike previous models, the double ABCX model recognises the fluid process of family adaptation. While capturing the initial processes employed by family members in direct response to the stressful event, the model also acknowledges the phase of adjustment that family members experience as the event unfolds. Thus, the double ABCX model aims to capture the natural progression of additional stressors, the development of resources, changes in appraisals, and the building of coping strategies as the stressor and family develop over time [6,21]. Second, unlike the limited focus of other models on either positive or negative outcomes, the double ABCX model accounts for a variety of experiences of family adaptation. Thus it is possible to examine parental outcomes that are both positive and negative in nature. Finally, the utility of the double ABCX model to explain successful adaptation in families of children with ASD has been demonstrated in a number of studies in diverse populations [e.g. 6, 28, 29, $30 \bullet \cdot$. As such, it was determined that this model provided for a comprehensive understanding of the process of adaptation which is the focus of this review.

Few studies have investigated the trajectory of factors included in the double ABCX model across child development. The current review aimed to clarify the changes in identified risk and protective factors in relation to child age to identify periods in which families require an increase in support and periods in which families appear to demonstrate greater adaptation to raising children with ASD. Due to the limited inclusion of fathers in ASD research [31•], the current findings provide a very one-sided view of family adaptation and the experiences of parents raising children with ASD. The review aimed to overcome such limitations by exploring, where possible, both similarities and differences between mothers and father's experiences to provide an understanding of how to best support successful adaptation in these families.

Peer-reviewed studies investigating factors associated with family adaptation (i.e. identified risk or protective factors in relation to raising children with $\mathrm{ASD}$, positive and/or negative 
parent or family outcomes) were included in the current review. Studies were not excluded based on specific criteria, but rather were examined for the following inclusion criteria: (a) contained data from primary caregivers of a child with ASD (i.e. mothers and/or fathers); (b) investigated study outcomes of parental stress, coping, quality of life, or wellbeing (i.e. depression, anxiety, mental health); (c) investigated child ASD symptom severity, child maladaptive/problem behaviour, child adaptive functioning, or general life stress in families; (d) investigated the marital relationship, family functioning, social support, or coping; and (e) assessed the Double ABCX model of family adaptation. Table 1 presents a summary of included studies, which utilise a cross-sectional design. Longitudinal studies included in this review are presented in Table 2.

Journal articles were identified through online searches of PsychINFO, Medline and Proquest Central with a focus of including articles published within the past three decades. Google Scholar search engines were also utilised. In addition, relevant articles, in line with inclusion criteria, were identified through searches in key journals (e.g. Autism, Journal of Autism and Developmental Disorders) and from the reference lists of all papers. Key search terms included: Autism, ASD, adaptation, stress, coping, parents, mother, father and wellbeing.

\section{The Double ABCX Model and ASD}

A number of researchers have examined the capacity of the double $\mathrm{ABCX}$ model to explain the process of raising a child with ASD. Since Bristol's [28] initial study, authors have attempted to expand the applicability of McCubbin and Patterson's model to capture the broadening impact of ASD on the family $[4,6]$, and the impact of parent gender on family adaptation $[30 \bullet \cdot$. The results from these studies have supported the utility of the double $\mathrm{ABCX}$ model in capturing a range of experiences of families raising children with ASD. This includes, but is not limited to, the demonstration of healthy levels of functioning in families, suggesting possible adaptation over time. A summary of methods and key findings are included in Table 1.

However, some limitations are evident. While many applications of the model have explored the combination of child ASD symptomatology and/or behaviour problems with life stress, child adaptive functioning (i.e. daily living skills), a characteristic which Hall and Graff [4] identified as demonstrating strong associations with adaptation in families of children with ASD, has not been investigated as an additional stressor in this model. Further, studies have tended to focus on an individualised view of family adaptation, focusing predominately on mother's reports of their own resources, appraisals, coping, and experiences of raising children with ASD. Consequently, few family-related variables have been explored in relation to this model resulting in gaps in the understanding of a family's process of adjustment to raising a child with ASD. Finally, only one study has focused on both positive and negative outcomes of adaptation in families. This research highlights that there is still much to be understood about the positive impact of raising a child with ASD, with the double ABCX model found to account for only $28 \%$ of the variance in family functioning [6]. Thus, clarity surrounding individual predictors of successful adaptation is required.

\section{Predictors of Family Adaptation}

Despite knowledge of the complexity of the adaptation process and the utility of a conceptual model to understand families' experiences, the role of potential risk (i.e. stressors), and protective factors (i.e. resources, appraisals, coping) in producing family outcomes (i.e. stress and wellbeing) remains unclear. Like family outcomes, these factors are suggested to vary significantly as children develop through infancy, childhood and adolescence [5]. This review will summarise the findings of risk and protective factors identified in McCubbin and Patterson's model, with a specific focus on how these factors may be impacted across the developmental trajectory.

\section{Stressors (aA)}

\section{Child Problem Behaviour}

In addition to the difficulties associated with the core impairments of ASD, many children also experience poor attention, and externalising and internalising behaviours. These behaviours are often referred to as maladaptive or problem behaviours separate from ASD symptomatology and symptom severity. Such behaviours have been found to consistently demonstrate positive associations with stress levels reported by parents raising children with ASD [e.g. 6, 15, 16, 37, 43, 49, $73,83,84,88]$, with suggestions that child behaviour is the strongest predictor of negative parent outcomes of all child related characteristics (referred to as child behaviour problems for the remainder of this review).

While the relationship between child problem behaviour and negative family outcomes has a strong evidence base, the majority of studies have focused on maternal report, failing to capture the experiences of other family members. In addition, research has not focused on child age restricting an understanding of changes in behavioural concerns over time. This is an important factor to address, with studies indicating that behavioural and emotional problems often decrease as children grow [82]. 


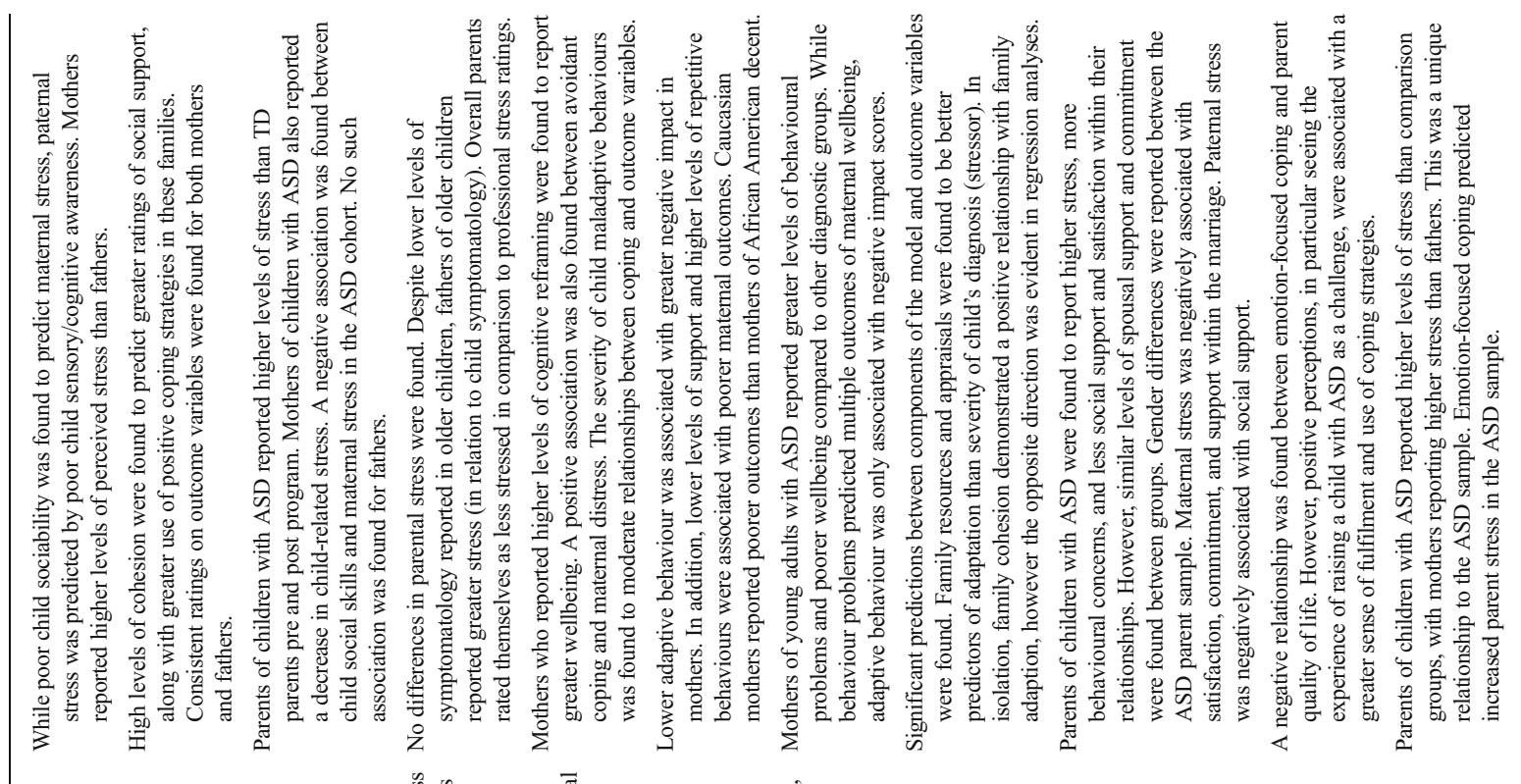

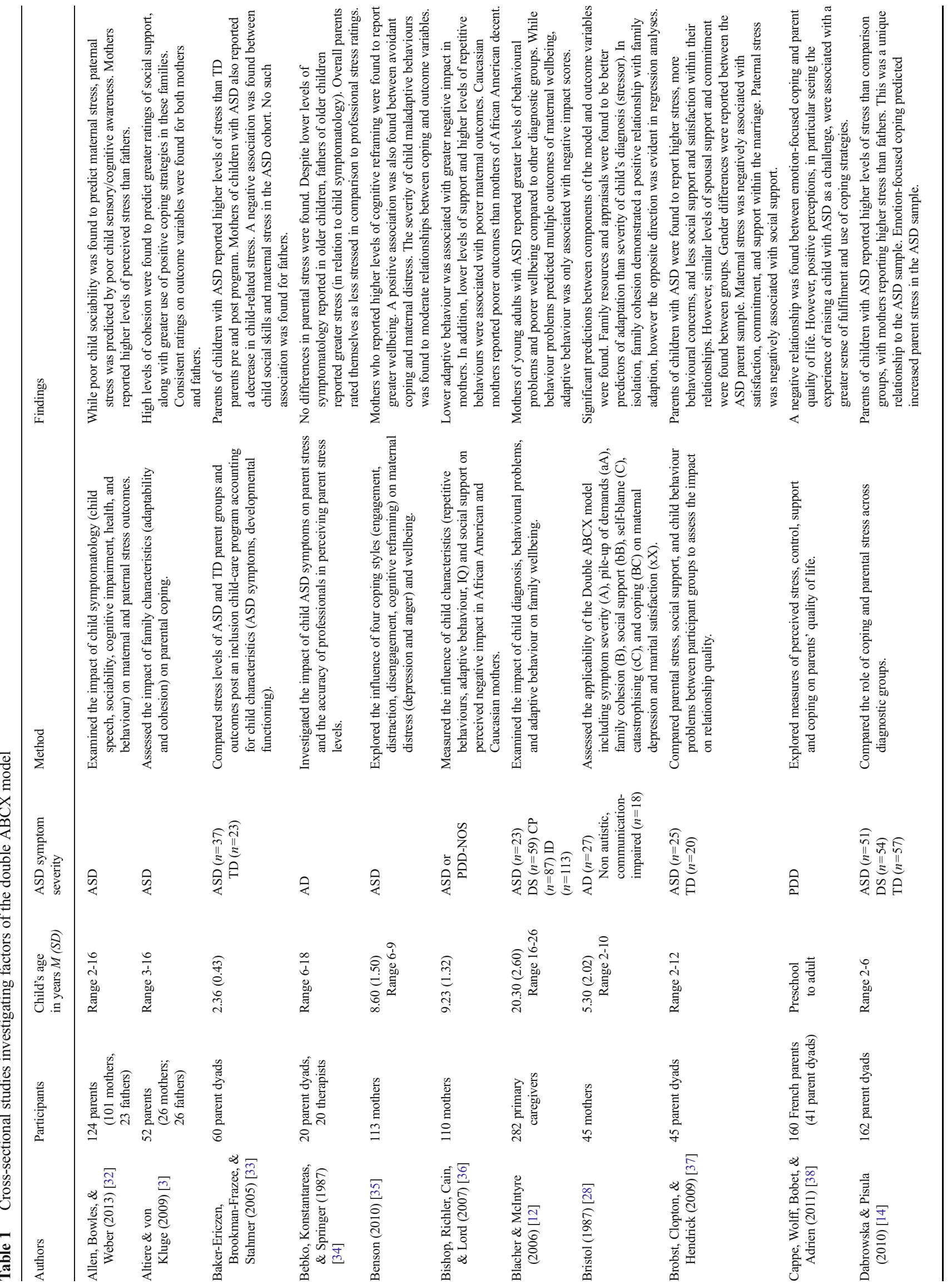




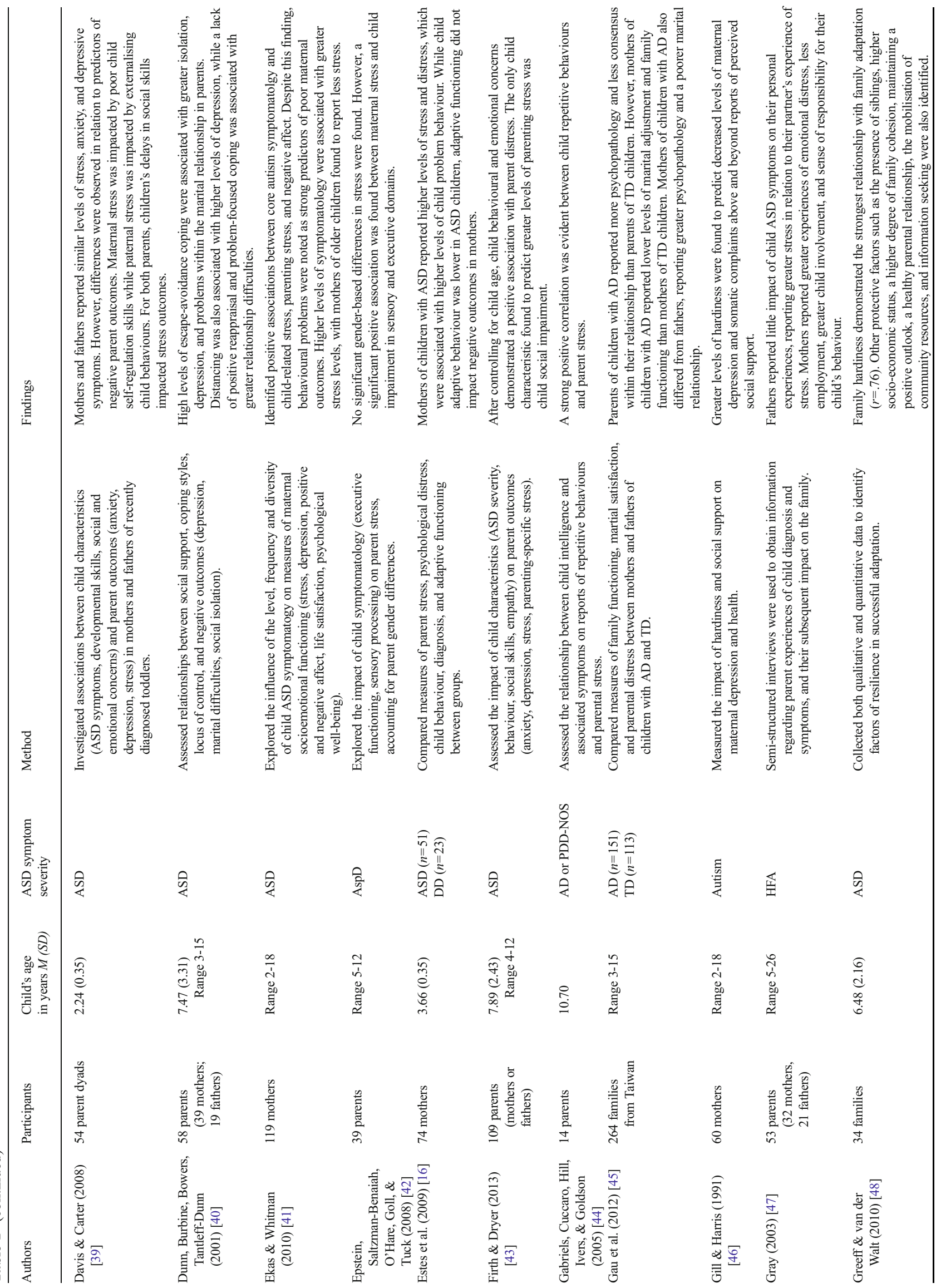




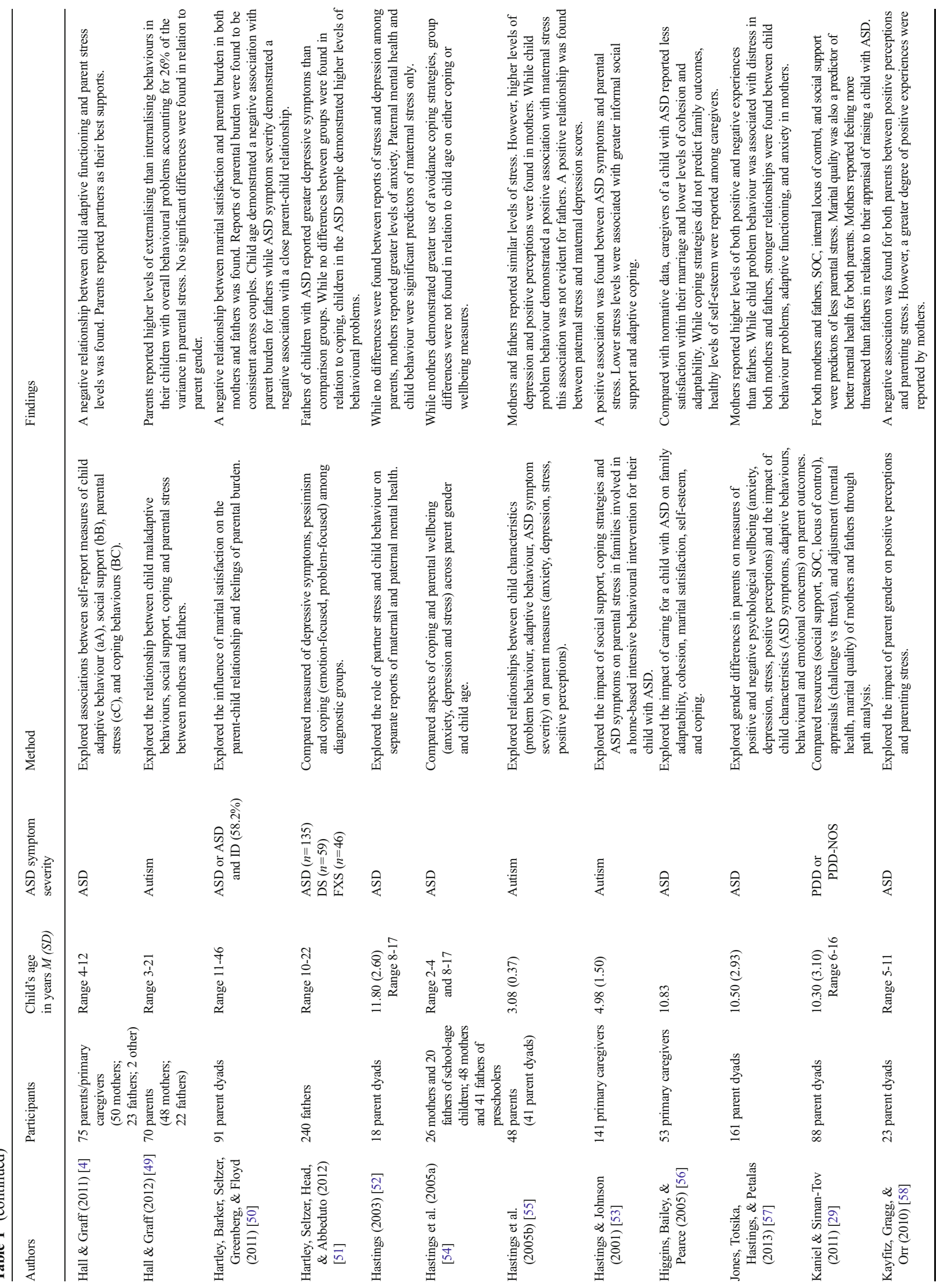




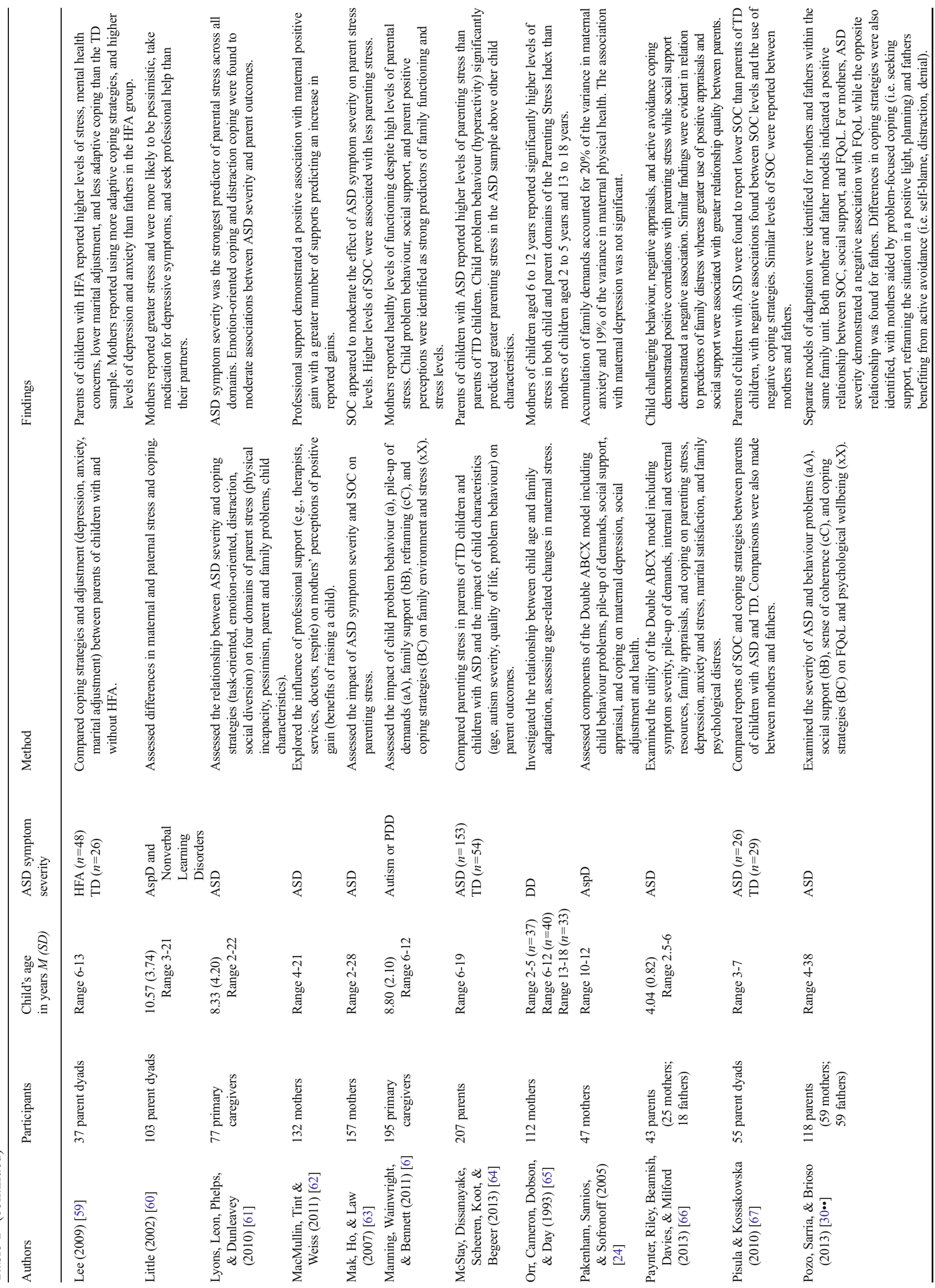




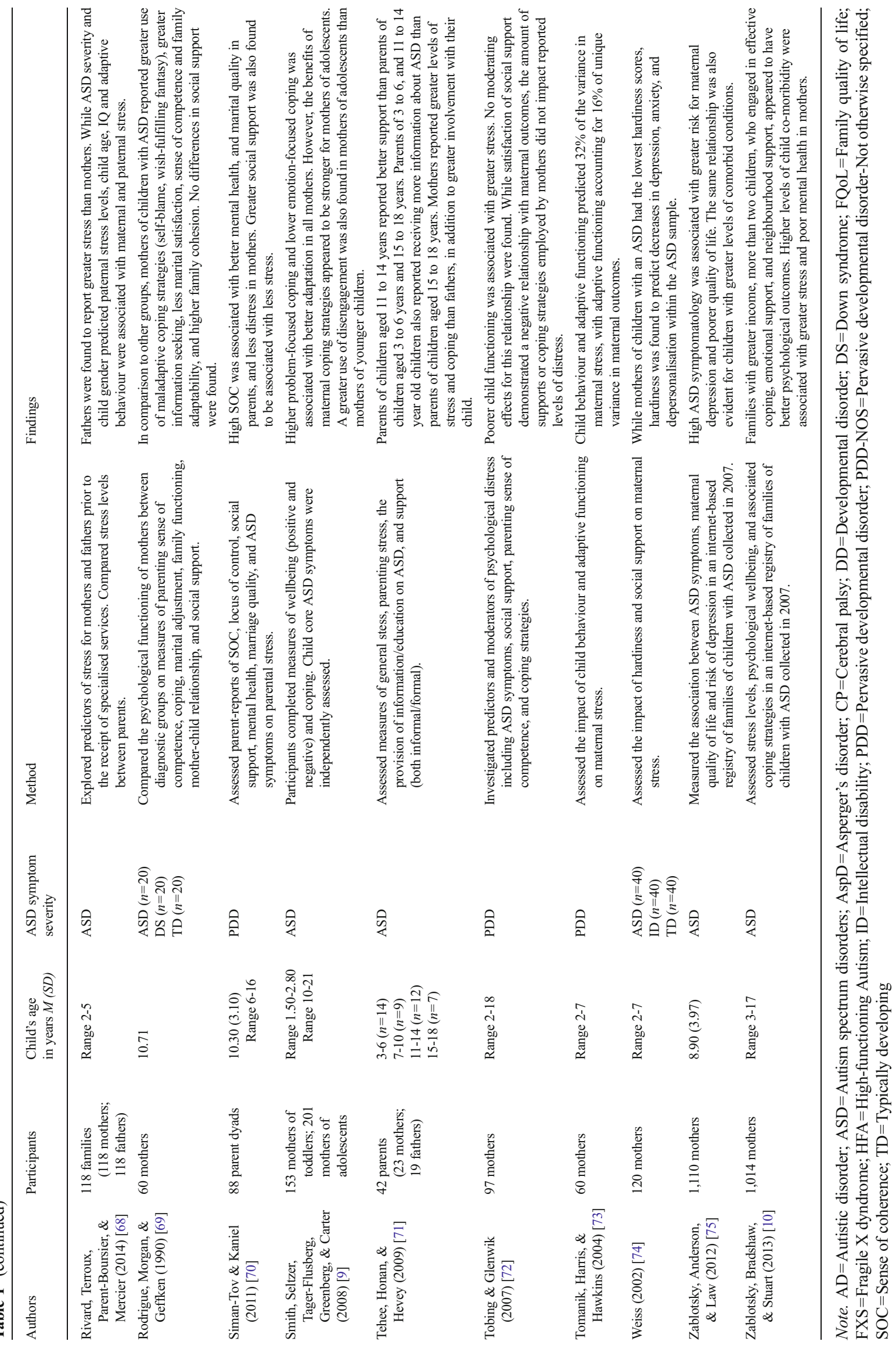




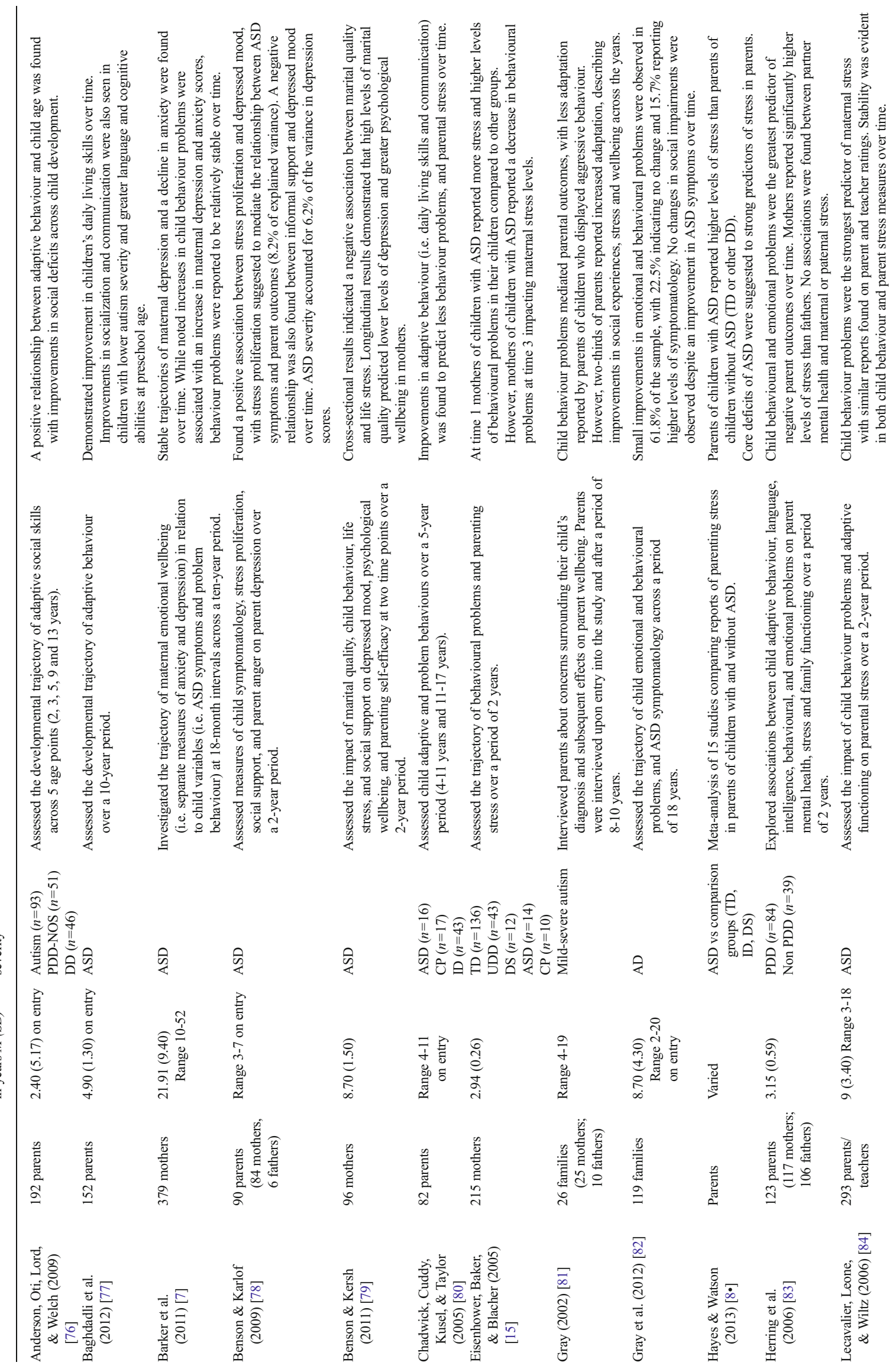




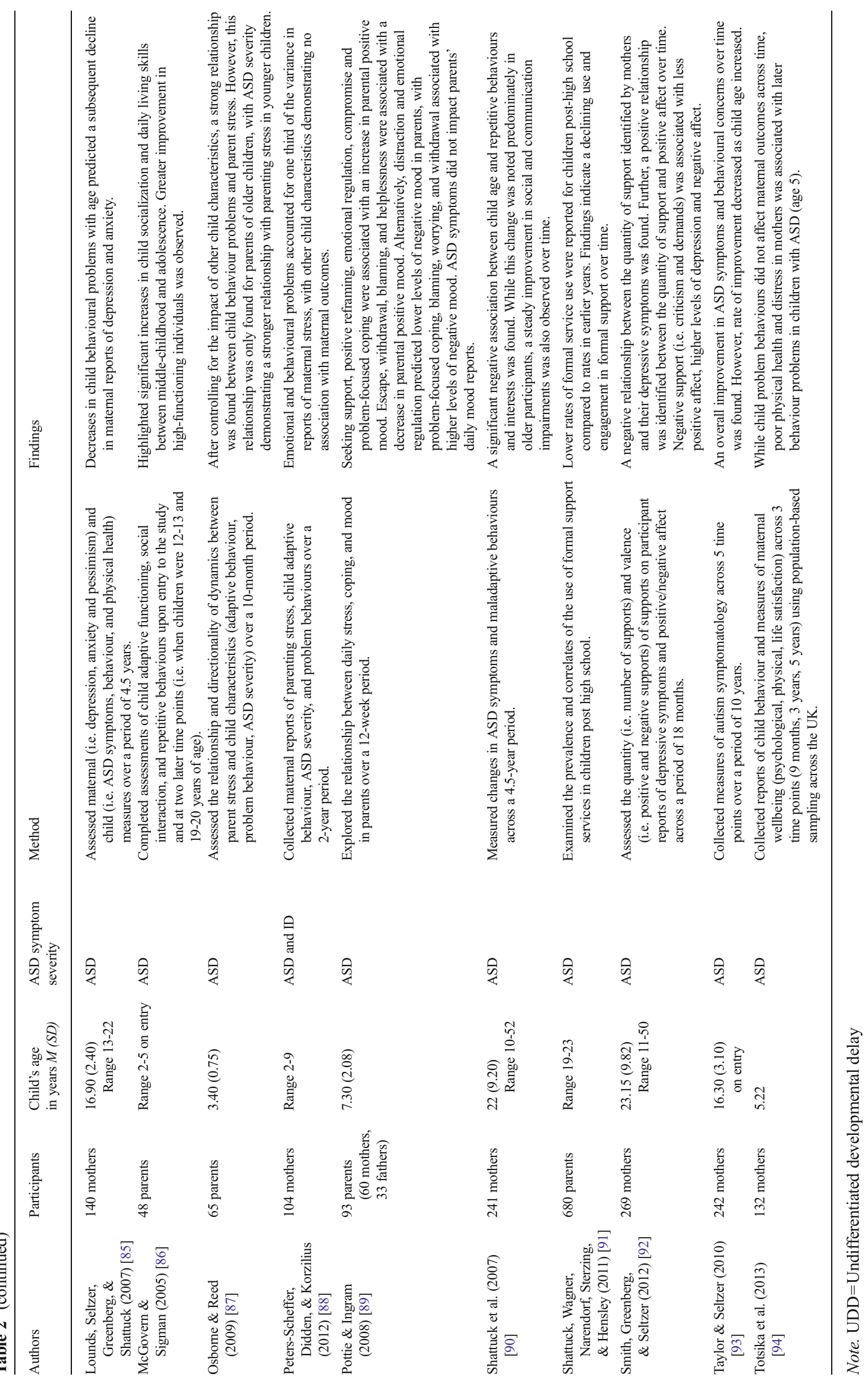


To date, those studies that have attempted to address the longitudinal impact of child behaviour problems on parent outcomes [e.g. 7, 15, 81, 85] suggest that child behaviour may mediate the degree of adaptation in mothers raising a child with ASD over time, with mothers of older children reporting greater wellbeing. While this research indicates that a decrease in risk factors may improve positive outcomes in parents, and vice versa, it is difficult to ascertain this trajectory across development due to current methodological limitations. A recent investigation of bidirectional relationships between child behaviour and maternal wellbeing in ASD, for example, has indicated that child behaviour problems had no effect on maternal reports of psychological distress, physical health and life satisfaction over a period of 2 years [94]. As this study employed population-defined sampling, a method in which participants were randomly selected from the population, it was suggested that the lack of findings may be due to the lower incidence of clinical levels of behavioural problems and maternal distress in the sample. This raises a question about the use of convenience sampling and other sampling biases that may impact study findings. Self-referral and the use of clinical populations is prominent in the ASD literature, with it being difficult to minimise such biases in research.

The use of distinct age ranges to assess the impact of child behaviour on maternal outcomes also limits the generalisability of findings. For example, some studies [e.g. 7,85 ] have focused solely on adolescent participants, where a longer period of time has lapsed between diagnosis and reports of current family functioning. In contrast, participants in Eisenhower et al.'s [15] research included parents of preschool children, limiting the generalisation of findings to parents of older school-age children with ASD. While Gray [81] addressed such limitations with his 10-year longitudinal study of both mothers and fathers, additional concerns are raised with initial data collected approximately two decades ago when the conceptualisation of autism was different to our current view. Consequently, further research addressing these concerns is needed to confirm the role of child age on behavioural outcomes. As research has also demonstrated that the impact of child problem behaviour on parental stress differs between mothers and fathers [39, 52], studies that address the role of parental gender in family adaptation are required.

\section{Autism Symptomatology}

Like child behaviour problems, the majority of studies examining carer and family outcomes indicate a positive association between the severity of a child's ASD symptoms and the stress experienced by family members [e.g. 8•, 33, 41, 44, 53, $61,72,75]$. However, it appears that this relationship may only be true when ASD symptom severity is measured in the absence of parental reports of additional child behaviour problems.
Research supports the view that child behaviour problems may override associations between ASD severity, or 'core symptoms', and family outcomes when included in the same analyses [e.g. 5, 6, 16, 64, 83, 88]. Thus it remains unclear which child characteristics most impact parent stress, supporting the need for specific and accurate measures of both child behaviour and core ASD symptoms to be included in studies [43]. Another consideration includes the development of ASD symptoms over time with improvement evident for older children with ASD $[90,93]$. While it is suggested that child ASD symptom severity may have a stronger impact on parental stress when children are of preschool age [87], the trajectory of ASD symptoms across childhood and their influence on mothers and father's wellbeing remains unclear.

\section{Adaptive Behaviour}

Studies investigating the impact of child adaptive functioning on families have yielded mixed results [e.g. 12, 36]. When measured in isolation, adaptive behaviour has been found to produce strong associations with family outcomes [e.g. 4]. However, like symptom severity, the relationship between adaptive behaviour and maternal outcomes may be masked by the inclusion of child problem behaviours [e.g. 55, 88] To date, these three child characteristics have not been examined together within the double ABCX model of family adaptation. Thus, the impact of each of these variables as potential stressors and their collective influence on both positive and negative family outcomes is unknown.

Like ASD symptomatology, evidence suggests that in children with ASD, adaptive behaviour improves as children age $[76,77,86]$. Only one study to date has investigated this relationship in relation to parental outcomes, emphasising the complex dynamic between child characteristics and parenting stress over time [80]. However, the small sample of children with ASD $(n=16)$ and the potential mediating role of child behaviour problems, limit the generalisability of findings. Despite knowledge of changes in child characteristics across child development, more information is required about subsequent adjustment in the family unit. Controlling the possible interaction of child characteristics may provide a clearer understanding of the role of each variable in predicting positive and negative family outcomes.

\section{Pile-up of Demands}

While child characteristics are identified as major stressors in the double $\mathrm{ABCX}$ model, additional stressors such as the pileup of family demands also impact families. Pile-up of demands refers to factors that may be indirectly related or unrelated to difficulties experienced as part of raising a child with ASD [21]. These may include financial hardships, emotional relationships between family members and modifications in 
family functioning. Such factors have been found to play an important role in family adaptation, significantly predicting maternal outcomes within the double ABCX model [28] and accounting for unique proportions of variance in negative family outcomes [24, 78]. However, once again, the majority of research has focused on the pile-up of demands on reports of maternal depression, limiting an understanding of the subsequent impact on fathers, parenting stress and family quality of life (FQoL).

Like child characteristics, secondary demands placed on families raising children with ASD are likely to change over time in relation to the child's particular developmental stage. To date, it appears that the pile-up of family demands may be greater in parents of children in middle childhood [24]; however further research is required to understand this trajectory and its implication of raising children in early adolescence. In addition, the extent to which family demands trigger a crisis in the family unit largely depends on the family's resources and appraisal of the event, with certain family environments (i.e. supportive and open) promoting more effective coping in families raising children with ASD [22].

\section{Resources (bB)}

Family resources are one factor suggested by the double ABCX model to influence the interaction between stressors and family adaptation. Family resources may make the family less vulnerable to stress and more resistant to the strains associated with raising a child with a disability. As resources are comprised of internal and external capabilities present within individuals, the family and the wider community [21], four key resources suggested to support families raising children with ASD include family hardiness, the family environment, marital support and social support. While resources pertaining to individual capabilities have been the focus of much past research, there is much to be said about the potential protective factors of aspects of the family unit, as discussed below.

\section{Family Hardiness}

Family hardiness is a term used to define the durability of the family unit, its sense of commitment, ability to see stressors as a challenge, and its sense of control [48]. This factor may also assist families in coping with raising children with ASD. Greeff and van der Walt [48] highlighted the importance of family hardiness on successful adaptation with strong positive associations found between hardiness and family attachment and changeability. However, caution must be exercised when interpreting these findings, with the majority of outcomes relying on correlational analyses in a small sample consisting of both dual and single parent families.
Only two other studies have investigated the impact of hardiness on mothers raising children with ASD. While hardiness was found to be associated with better mental health and stress outcomes, these studies capture hardiness in individuals rather than hardiness within the family unit $[46,74]$. Moreover, no study to date has investigated the association between child age, family hardiness and family outcomes leaving many questions unanswered about the role of family hardiness as a coping resource across key stages in child development.

\section{Family Environment}

The family environment is defined as the extent to which family members support each other, are open and express their feelings towards one another [95]. The majority of studies have investigated the family environment as an outcome variable in families raising children with ASD [6, 48, 56, 83]. Only one study has considered the family environment as a protective factor, assisting coping within families. Bristol [96] reported high levels of cohesion and expressiveness among parents of children with ASD to be associated with greater competence and acceptance of the child, and greater marital happiness, respectively. However, no research has investigated the influence of the family environment on stress and FQoL.

Evidence suggests that cohesion may be a particularly important resource within the family environment. This factor captures the support family members provide one another in raising a child with ASD, and can be described on a continuum of enmeshment and disengagement [3]. Although moderate levels of cohesion are suggested to be beneficial to families raising children with a disability [97], findings indicate that higher levels of cohesion (i.e. families who are excessively involved with the lives of their children and very protective) may be beneficial for adaptation in families of children with $\operatorname{ASD}[3,48,69]$.

What remains unclear, however, is whether different levels of cohesion are beneficial at different stages of a child's life. High levels of cohesion, for example, may be a positive resource for families during times of dramatic change, such as initial diagnosis or transition to school, where children need extra support around developing skills and adapting to change. Such high levels may be less helpful in other stages of development (e.g. middle childhood) when the family may have settled and children have the opportunity to develop more independence and growth [3]. The ambiguity surrounding optimum levels of cohesion in families of children with an ASD highlight the need to understand the family environment across periods of child development, a factor unaccounted for in studies to date.

\section{Marital Relationship}

In addition to resources associated with the family environment and the strength of relationships between family 
members, the strength of the marital relationship is an important form of support to families. Evidence suggests that spousal support is associated with fewer depressive symptoms, higher relationship quality and greater child acceptance in families raising children with ASD [96]. In addition, spouses have been rated as the most important support system in these families $[4,70]$. Two studies to date have investigated the role of the marital relationship at different stages of child development, demonstrating the continued importance of spousal support over time $[50,79]$ with higher levels of satisfaction within the marital relationship associated with less stress and burden among parents. Once again, one major limitation of these studies was the large age ranges of children included in the samples. This may confound study outcomes in relation to determining the trajectory of marital adjustment over time. Although addressing the experiences of parents of adolescents and adults with ASD, the findings cannot be generalised to parents of preschoolers or school-aged children.

Like the family environment, many studies have focused on the marital relationship as an outcome variable of family adaptation, indicating less marital satisfaction in mothers of children with ASD in comparison to mothers of children with other disorders [56, 69], and less positive expression within the marital relationship [45]. While current findings suggest spousal support plays a mediating role in family adaptation, greater understanding of the importance of the marital relationship in families of young children with ASD are needed, including its potential as a protective factor, in successful adaptation.

\section{Social Support}

Numerous studies have highlighted the positive impact of a supportive environment for families raising children with ASD. These studies suggest that social support may act as a buffer against the negative impact of stressors, with social support found to be associated with lower maternal distress, depression, negative affect, and stress, and greater use of positive coping strategies and adjustment $[6,29,30 \bullet, 38,53,70$, $72,78]$. The type and number of supports available have also been shown to impact study findings [92], with a greater number of positive supports found to improve family outcomes.

While the positive impact of informal support networks (i.e. family and friends) has been well established, limited research has investigated the role of formal support services (i.e. professionals, other services) [5]. This gap is surprising considering the suggested reduction in the number of formal supports available to families over time $[81,91]$ and the reported association between professional support and positive outcomes in mothers of children with ASD aged 4 to 21 years [62].

The stage of the child's development may influence the impact of support perceived by the family. Middle childhood is a stage where parents have reported feeling most supported by friends and services [71]. However, few studies have investigated the variable of child age on support networks. Due to the limitations of Tehee et al.'s [71] study (i.e. small sample, lack of relationship between child age, support, and stress measures and unknown impact of child characteristics such as problem behaviour or ASD severity on study outcomes), research that builds on these initial findings is required. Thus, more detailed analysis into the benefits of formal support and the role of social support over time is important to understand the global impact of social support and its apparent protective status to families raising children with ASD.

\section{Appraisal (cC)}

Appraisals encapsulate the manner in which families perceive and interpret the stressor event (e.g. in a negative or positive light), incorporating a family's view about their ability to address the stressor and whether it is something worth overcoming [6]. Many variables have been investigated as a form of appraisal in previous studies examining the double ABCX model in families of children with ASD. These include self-blame and catastrophising [28]; challenge and threat [29]; reframing [6]; parental stress $[4,24,49,70]$; the implications of raising a child with ASD [66]; and sense of coherence (SOC) [30].

While high SOC has been associated with positive outcomes in families $[29,30 \bullet, 70]$ and has been suggested to mediate relationships between stressors and family outcomes [63], parents of children with ASD have been found to report lower levels of SOC than other families [67]. However, once again, these studies fail to account for changes in appraisals across different stages of a child's development. In addition, they do not assess 'family' appraisals in their measures of SOC. In order to understand this perception of family life a measure of family SOC is required.

Family sense of coherence (FSOC) extends the definition of SOC to encapsulate a family's assumptions of the family unit and the outside world, including the resources available to it and the ability to manage stressful situations (i.e. that they are manageable, meaningful and comprehensive) [98]. By viewing the challenges associated with their child's diagnoses in a positive light, families may attribute meaning to their situation, thereby facilitating the selection of appropriate coping styles and subsequent adaptation [24, 70, 98].

Findings from the wider disability literature indicate that higher levels of FSOC are related to greater adaptation and a higher level of reorganisation following crises [98]. In addition, FSOC has demonstrated strong associations with FQoL and acted as a significant mediator between illness stress and quality of life [99]. Further, FSOC has been found to account for up to $35 \%$ of the variance in family adaptation [100]. Despite these outcomes, no study has explored the impact of 
FSOC on families raising children with ASD, or investigated possible changes in the impact of FSOC over time, or its relationship with other variables in the double $\mathrm{ABCX}$ model.

\section{Coping (BC)}

Coping is the factor in the double ABCX model that connects resources, appraisals and behavioural strategies to restore a balance in family functioning [6,24]. This may involve reducing demands, seeking new or maintaining useful resources, or changing the meaning of the stressor event [21]. Coping has been widely studied in the ASD literature with both quantitative and qualitative research attempting to define the most beneficial strategies to assist families in raising children with ASD. To date, these strategies remain unclear, determined by a number of contextual factors [61]. However, there is evidence to suggest that problem-focused coping (i.e. actions which aim to solve problematic situations) and positive reframing (i.e. reinterpreting a problem in a positive light) are associated with reports of greater parental wellbeing in families of children with ASD [e.g. 6, 35, 38, 40, 55, 59, 61, 89].

Studies have also investigated parental coping over time with mixed findings. Despite some studies indicating no age affects [54], Smith et al. [9] provide valuable information about differences in maternal coping at specific stages of child development. In their study, mothers of older children engaged in greater detachment from stressors, and reported higher levels of anger compared to mothers of toddlers. However, it is unclear whether differences in sample cohorts may have contributed to study outcomes (e.g. mothers of younger children were more likely to be married and receive higher incomes). In addition, the findings may not be able to be generalized to parents of children aged between 4 and 10 years of age, and, possible differences in parental coping are unknown with data collected solely from maternal caregivers. Such restrictions limit the generalisability of study outcomes. In particular, little remains known about the critical stage when many children are entering the school system.

The coping literature demonstrates the importance of contextual factors such as parent gender [e.g. 30••] and child age in the process of successful family adaptation. However, like other factors in the double ABCX model, gaps still exist regarding the use of paternal reports and an understanding of coping as children develop.

\section{Family Adaptation (xX)}

Both positive and negative outcomes co-occur in families raising children with an ASD. Predicted by different factors, it is important to distinguish both outcomes as separate measures of family adaptation $[18,101]$. To date, family adaptation has been conceptualised by measures of the family environment [e.g. 6], parental stress [e.g. 6, 65], maternal depression [e.g. 28], marital adjustment [e.g. 28, 56], quality of parenting [e.g. 28] and family attachment and changeability [e.g. 48]. Thus, the definition and operationalisation of family adaptation varies from study to study. Mothers and father's experiences of adaptation are also unclear with some studies suggesting higher levels of both negative (e.g. stress and depression) and positive outcomes (e.g. positive perceptions/experiences) in mothers [14, 55, 58], and others suggesting no reported differences [e.g. 39, 52].

Unlike other constructs used to measure family adaptation, FQoL is a recent measure developed to capture the importance and satisfaction of different aspects of family life from the perspective of family members. Family quality of life has been associated with child behaviour problems, social support, SOC and psychological wellbeing in parents of children with ASD. It is conceptualised as a positive outcome variable and has been shown to relate to different predictors of mother and father adaptation $[30 \bullet \bullet]$. While preliminary evidence suggests an association between child age and family adaptation, no research to date has explored FQoL across child development.

Stress is a measure of family adaptation which has received more attention (than FQoL). However, results to date have been inconsistent, with some studies suggesting higher stress in parents of younger children [e.g. 7, 81, 85], some studies indicating no age-related effects [e.g. 54, 84, 88], and other studies suggesting differences in parent gender and child age [e.g. 34]. One study investigated the trajectory of maternal stress, focusing on mothers of children in preschool, middle childhood, and adolescence [65]. While the findings indicated a variable pattern of maternal stress across child development, participants included mothers of children with developmental disorders where data was not available for all age cohorts (i.e. behaviour problems in children aged 2 to 5 years).

By charting the change in stressors, resources, appraisals and positive outcomes over time, information regarding potential risk and protective factors for successful adaptation, captured by FQoL measures, can be explored. However, to date, the majority of studies have employed designs focused on a range of different predictors of the outcomes of one family member. The recent findings of gender differences in parental experiences of adaptation prompt greater exploration into the role of mothers and fathers in raising children with ASD.

\section{The Role of Parent Gender}

Like mothers, fathers of children with ASD have been found to demonstrate higher levels of stress than fathers of children without ASD [8・ 14, 33, 37, 51]. However, in a recent review investigating the involvement of fathers in ASD, Braunstein and colleagues [31•] concluded that despite child age, journal type, or publication date, fathers were rarely included in studies assessing the impact of raising a child with ASD on parents.

The limited studies that have included both parents in investigations of family outcomes demonstrate mixed results. 
The majority of studies indicate that mothers experience greater stress levels than fathers $[14,47,57,60,71,83]$, which may be the result of greater involvement with the child [71]. Nonetheless, some research has also suggested similar experiences of stress between parents [39, 52, 55]. While in some studies fathers have been found to report no direct impact of child characteristics on their subsequent wellbeing [47], in others, fathers report higher levels of stress than mothers [68]. This suggests that there is still much to be explained about the experiences of parents raising children with ASD. Parental roles within the family, for example, may influence the experiences of mothers and fathers, with differences in occupation and time spent with the child found to impact parent outcomes in families raising children with ASD [47, 71].

In addition to differences in the experience of stress, maternal and paternal outcomes have been shown to be affected by different predictors. Maternal stress, for example, has been attributed to a number of child characteristics including greater emotional dysregulation [39], poor social skills [32, 33], executive dysfunction and sensory difficulties [42] and increases in behaviour problems [52, 55, 57]. Relationship factors including lower levels of relationship satisfaction and spousal support [37] have also been identified as sources of stress in mothers. Alternatively, fathers report higher levels of stress in relation to child externalising behaviours [39, 57], ASD symptoms [68], poor child sensory and cognitive awareness [32] and less social support [37]. Together, both parents have been found to demonstrate positive relationships between child social deficits [39], partner mental health $[47,52,55]$ and parent stress.

Parents also report disparities in the strategies employed to cope with raising a child with ASD. Specifically, mothers have been found to report more positive experiences in relation to raising their child than fathers [58], and a greater use of positive and problem-focused coping [59]. Greater reports of avoidance coping [54] and feeling threatened by the challenge of raising a child with ASD have also been found [29] for mothers. Fathers, on the other hand, report engaging more frequently in active avoidance coping [30••]. While this research highlights the different experiences of mothers and fathers in raising children with ASD, few studies have compared parental reports of family adaptation through the use of the double ABCX model [e.g. 4, 29, 30••]. In turn, these studies have investigated different stressors, appraisals and outcomes of adaptation, making it difficult to compare and interpret study findings.

\section{Summary and Conclusions}

The heightened stress and strain placed on families raising a child with ASD has been consistently highlighted in studies comparing families of children with ASD to control groups.
Research has demonstrated that families have to manage competing child related stressors such as increased maladaptive behaviour and impairments in communication, social skills and adaptive functioning. In addition, they may be equipped with less personal and family resources (e.g. lower marital satisfaction and social support), a lower propensity to view their situation as meaningful, manageable and comprehensive, and demonstrate greater use of maladaptive coping strategies. Each of these aspects appear to impact the success of a family in adapting to raising a child with ASD, and play a role in protecting against or increasing the risk of negative family outcomes.

Despite this evidence, families have demonstrated resilience and adaptation in the face of identified stressors. These findings raise a number of questions about the breadth of family experiences and key contributing factors for positive family outcomes. However, there are a number of methodological limitations that confound the generalisability of the findings to date, in particular the conceptualisation and measurement of family experiences. This is an important factor to consider when referencing the double ABCX model and considering the overlap of variables included in analyses. As previously noted, the need for separate and distinct tools to differentiate core ASD symptoms from measures of maladaptive and adaptive behaviour may provide clarity to the current overlap between child characteristics and their influence on family outcomes. Also, measurement of family experiences often provides similar conceptual overlap between family resources, appraisals, coping strategies and adaptation. Further, the definition of adaptation is variable in individual studies with a number of predictor variables often defined as outcomes of adaptation and vice versa. As a result, further clarification of the rationale for and validity of constructs used in this area is required to determine potential risk and protective factors for families in order to develop appropriate support and intervention resources.

Limited longitudinal research has demonstrated the fluid nature of child and family experiences over time. Generally, child characteristics have been shown to improve as children develop, with some evidence of a positive impact on parental outcomes. However, this evidence is sparse and more research is needed to capture changes in family resources, appraisals and positive experiences over phases of child development. Although, a number of studies have attempted to address the impact of child age on family outcomes, findings are generally focused on specific (e.g. adolescence) or global (e.g. children aged 2 to 18 years) stages of development. This limits interpretation of the trajectory of family experiences over time, especially considering the use of multiple constructs, designs, and samples used in current research.

A recently acknowledged and growing area of focus is the impact of raising a child with ASD on the family system, broadening the understanding of experiences to other family 
members, in particular, fathers. The importance of this shift in parent report is demonstrated by findings of significant gender related differences in parent's perceptions, resources, identified stressors, and coping strategies in raising a child with ASD. Information from both parents is essential for developing programs to support parents, and can highlight the need to consider different models of support for mothers and fathers. However, these findings remain unclear particularly in regards to the double ABCX model.

In order to address the question of how to better support families raising children with ASD, further understanding of family experiences are required in a number of critical domains. Specifically, 1) a greater focus on factors that promote resiliency in individual family members and the family unit; 2) specific measurement of stressors, resources, appraisals, coping and adaptation; 3) research examining positive and negative experiences of mothers and fathers with a focus on the specific predictors of each outcome; and 4) measurement across the developmental trajectory.

Due to the fluidity of family needs, particular resources and coping strategies may be beneficial to families at different stages of child development within different family members. Thus utilising a theoretical framework that incorporates both the challenges and rewards of raising children with ASD will assist in the development of appropriate support services to be implemented at these time points. While no model will account for the myriad of experience of individual families, the results from this more holistic approach have the potential to determine effective coping strategies, and inform stakeholders and policy makers about risk and protective factors. Further information about how to improve family outcomes may also serve to reduce the long-term economic costs of education and care for families of children with an ASD.

\section{Compliance with Ethics Guidelines}

Conflict of Interest Rebecca L. McStay, David Trembath and Cheryl Dissanayake declare that they have no conflict of interest.

Human and Animal Rights and Informed Consent This article does not contain any studies with human or animal subjects performed by any of the authors.

\section{References}

Papers of particular interest, published recently, have been highlighted as:

- Of importance

•. Of major importance

1. American Psychiatric Association. Diagnostic and Statistical Manual of Mental Disorders (5th edn.). Washington, DC: Author. 2013.
2. Centers for Disease Control and Prevention. 2014. Data and Statistics. Retrieved from http://www.cdc.gov/ncbddd/autism/ data.html.

3. Altiere MJ, von Kluge S. Family functioning and coping behaviours in parents of children with autism. J Child Fam Stud. 2009;18:83-92. doi:10.1007/s10826-008-9209-y.

4. Hall HR, Graff JC. The relationships among adaptive behaviors of children with autism, family support, parenting stress, and coping. Issues Compr Pediatr Nurs. 2011;34:4-25. doi:10.3109/ 01460862.2011. 555270.

5. Karst JS, Van Hecke AV. Parent and family impact of autism spectrum disorders: a review and proposed model for intervention evaluation. Clin Child Fam Psychol Rev. 2012;15:247-77. doi:10. 1007/s10567-012-0119-6.

6. Manning MM, Wainwright L, Bennett J. The double ABCX model of adaptation in racially diverse families with a school-age child with autism. J Autism Dev Disord. 2011;41:320-31. doi:10.1007/ s10803-010-1056-1.

7. Barker ET, Hartley SL, Seltzer MM, Floyd FJ, Greenberg JS, Orsmond GI. Trajectories of emotional well-being in mothers of adolescents and adults with autism. Dev Psychol. 2011;47:55161. doi:10.1037/a0021268.

8. Hayes SA, Watson SL. The impact of parenting stress: a metaanalysis of studies comparing the experience of parenting stress in parents of children with and without autism spectrum disorder. J Autism Dev Disord. 2013;43:629-42. doi:10.1007/s10803-0121604-y. This systematic review provides further evidence for the increased levels of stress in parents of children with ASD in comparison to control groups supporting reports from individual studies.

9. Smith LE, Seltzer MM, Tager-Flusberg H, Greenberg JS, Carter AS. A comparative analysis of wellbeing and coping among mothers of toddlers and mothers of adolescents with ASD. J Autism Dev Disord. 2008;38:876-89. doi:10.1007/s10803-0070461-6.

10. Zablotsky B, Bradshaw CP, Stuart EA. The association between mental health, stress, and coping supports in mothers of children with autism spectrum disorders. J Autism Dev Disord. 2013;43: 1380-93. doi:10.1007/s10803-012-1693-7.

11. Abbeduto L, Seltzer MM, Shattuck P, Krauss MW, Orsmond G, Murphy MM. Psychological wellbeing and coping in mothers of youths with autism. Down syndrome or fragile X syndrome. Am J Ment Retard. 2004;109:237-54.

12. Blacher J, McIntyre LL. Syndrome specificity and behavioural disorders in young adults with intellectual disability: cultural differences in family impact. J Intellect Disabil Res. 2006;50:184 98. doi:10.1111/j.1365-2788.2005.00768.x.

13. Bouma R, Schweitzer R. The impact of chronic childhood illness on family stress: a comparison between autism and cystic fibrosis. J Clin Psychol. 1990;46:722-30.

14. Dabrowska A, Pisula E. Parenting stress and coping styles in mothers and fathers of pre-school children with autism and Down syndrome. J Intellect Disabil Res. 2010;54:266-80. doi: 10.1111/j.1365-2788.2010.01258.x.

15. Eisenhower AS, Baker BL, Blacher J. Preschool children with intellectual disability: syndrome specificity, behaviour problems, and maternal well-being. J Intellect Disabil Res. 2005;49:657-71. doi:10.1111/j.1365-2788.2005.00699.x.

16. Estes A, Munson J, Dawson G, Koehler E, Xiao-Hua Z, Abbott R. Parenting stress and psychological functioning among mothers of preschool children with autism and developmental delay. Autism. 2009;13:375-87. doi:10.1177/1362361309105658.

17. Quintero N, McIntyre LL. Sibling adjustment and maternal wellbeing: an examination of families with and without an autism spectrum disorder. Focus Autism Other Dev Disabil. 2010;25: 37-46. doi:10.1177/1088357609350367. 
18. Hastings RP, Taunt HM. Positive perceptions in families of children with developmental disabilities. Am J Ment Retard. 2002;107:116-27. doi:10.1352/0895-8017(2002)107.

19. Bayat M. Evidence of resilience in families of children with autism. J Intellect Disabil Res. 2007;51:702-14. doi:10.1111/j.13652788.2007.00960.x.

20. Bekhet AK, Johnson NL, Zauszniewski JA. Resilience in family members of persons with autism spectrum disorder: a review of the literature. Issues Ment Health Nurs. 2012;33:650-6. doi:10. 3109/01612840.2012.671441.

21. McCubbin HI, Patterson JM. The family stress process. Marriage Fam Rev. 1983;6:7-37.

22. Morgan SB. The autistic child and family functioning: a developmental-family systems perspective. J Autism Dev Disord. 1988;18:263-80. doi:10.1007/BF02211952.

23. Kazdin AE, Kraemer HC, Kessler RC, Kupfer DJ, Offord DR. Contributions of risk-factor research to developmental psychopathology. Clin Psychol Rev. 1997;17:375-406.

24. Pakenham KI, Samios C, Sofronoff K. Adjustment in mothers of children with Asperger syndrome: an application of the double ABCX model of family adjustment. Autism. 2005;9:191-212. doi:10.1177/1362361305049033.

25. Hill R. Families under stress. New York: Harper \& Row; 1949.

26. Lazarus RS, Folkman S. Stress, appraisal, and coping. Berlin: Springer; 1984

27. Luthar S, Cicchetti D, Becker B. The construct of resilience: a critical evaluation and guidelines for future work. Child Dev. 2000;71:543-62. doi:10.1111/1467-8624.00164.

28. Bristol MM. Mothers of children with autism or communication disorders: successful adaptation and the double ABCX model. J Autism Dev Disord. 1987;14:469-86. doi:10.1007/BF01486964.

29. Kaniel S, Siman-Tov A. Comparison between mothers and fathers in coping with autistic children: a multivariate model. Eur J Spec Needs Educ. 2011;26:479-93. doi:10.1080/08856257.2011. 597186.

$30 . \bullet$ Pozo P, Sarria E, Brioso A. Family quality of life and psychological well-being in parents of children with autism spectrum disorders: a double ABCX model. J Intellect Disabil Res. 2013. doi:10. 1111/jir.12042. The article was the frist to explore positive and negative outcomes of family adaptation through separate path analyses of components of the Double ABCX model. The study also explored the experiences of mothers and fathers demonstrating specific findings for each gender.

31. Braunstein VL, Peniston N, Perelman A, Cassano MC. The inclusion of fathers in investigations of autistic spectrum disorders. Res Autism Spectr Disord. 2013;7:858-65. doi:10.1016/j.rasd.2013. 03.005. This article addressed the lack of paternal report in ASD research through a comprehensive review of the literature, highlighting the need for an increased understanding of paternal experiences in this field.

32. Allen KA, Bowles TV, Weber LL. Mothers' and fathers' stress associated with parenting a child with autism spectrum disorder. Autism Insights. 2013;5:1-11. doi:10.4137/AUI.S11094.

33. Baker-Ericzen MJ, Brookman-Frazee L, Stahmer A. Stress levels and adaptability in parents of toddlers with and without autism spectrum disorders. Res Pract Pers Sev Disabil. 2005;30:194-204.

34. Bebko JM, Konstantareas MM, Springer J. Parent and professional evaluations of family stress associated with characteristics of autism. J Autism Dev Disord. 1987;17:565-76. doi:10.1007/ BF01486971.

35. Benson PR. Coping, distress, and wellbeing in mothers of children with autism. Res Autism Spectr Disord. 2010;4:217-28. doi:10. 1016/ j.rasd.2009.09.008.

36. Bishop SL, Richler J, Cain AC, Lord C. Predictors of perceived negative impact in mothers of children with autism spectrum disorder. Am J Ment Retard. 2007;112:450-61. doi:10.1352/ 0895-8017(2007)112.

37. Brobst JB, Clopton JR, Hendrick SS. Parenting children with autism spectrum disorders: the couple's relationship. Focus Autism Other Dev Disabil. 2009;24:38-49. doi:10.1177/ 1088357608323699

38. Cappe E, Wolff M, Bobet R, Adrien JL. Quality of life: a key variable to consider in the evaluation of adjustment in parents of children with autism spectrum disorders and in the development of relevant support and assistance programs. Qual Life Res. 2011;20: 1279-94. doi:10.1007/s11136-011-9861-3.

39. Davis NO, Carter AS. Parenting stress in mothers and fathers of toddlers with autism spectrum disorders: associations with child characteristics. J Autism Dev Disord. 2008;38:1278-91. doi:10. 1007/s10803-007-0512-z.

40. Dunn ME, Burbine T, Bowers CA, Tantleff-Dunn S. Moderators of stress in parents of children with autism. Community Ment Health J. 2001;37:39-52.

41. Ekas N, Whitman TL. Autism symptom topography and maternal socioemotional functioning. Am J Intellect Dev Disabil. 2010;115:234-49. doi:10.1352/1944-7558-115.3.234.

42. Epstein T, Saltzman-Benaiah J, O'Hare A, Goll JC, Tuck S. Associated features of Asperger syndrome and their relationship to parenting stress. Child Care Health Dev. 2008;34:503-11. doi: 10.1111/ j.1365-2214.2008.00834.x.

43. Firth I, Dryer R. The predictors of distress in parents of children with autism spectrum disorder. J Intellect Dev Disabil. 2013;38: 163-71. doi:10.3109/13668250.2013.773964.

44. Gabriels RL, Cuccaro ML, Hill DE, Ivers BJ, Goldson E. Repetitive behaviours in autism: relationships with associated clinical features. Res Dev Disabil. 2005;26:169-81. doi:10. 1016/j.ridd.2004.05.003.

45. Gau SS, Chou M, Chiang H, Lee J, Wong C, et al. Parental adjustment, marital relationship, and family function in families of children with autism. Res Autism Spectr Disord. 2012;6:263-70. doi:10.1016/j.rasd.2011.05.007.

46. Gill MJ, Harris SL. Hardiness and social support as predictors of psychological discomfort in mothers of children with autism. J Autism Dev Disord. 1991;21:407-16. doi:10.1007/BF02206867.

47. Gray DE. Gender and coping: the parents of children with high functioning autism. Soc Sci Med. 2003;56:631-42.

48. Greeff AP, van der Walt K. Resilience in families with an autistic child. Educ Train Autism Dev Disabil. 2010;45:347-55.

49. Hall HR, Graff JC. Maladaptive behaviours of children with autism: parent support, stress and coping. Issues Compr Pediatr Nurs. 2012;35:194-214. doi:10.3109/01460862. 2012.734210.

50. Hartley SL, Barker ET, Seltzer MM, Greenberg JS, Floyd FJ. Marital satisfaction and parenting experiences of mothers and fathers of adolescents and adults with autism. Am J Intellect Dev Disabil. 2011;116:81-95. doi:10.1352/1944-7558-116.1.81.

51. Hartley SL, Seltzer MM, Head L, Abbeduto L. Psychological wellbeing in fathers of adolescents and young adults with down syndrome, fragile x syndrome and autism. Fam Relat. 2012;61: 327-42. doi:10.1111/j.1741-37.29.2011.00693.x.

52. Hastings RP. Child behaviour problems and partner mental health as correlates of stress in mothers and fathers of children with autism. J Intellect Disabil Res. 2003;47:231-7. doi:10.1046/j. 1365-2788.2003.00485.x.

53. Hastings RP, Johnson E. Stress in UK families conducting intensive home-based behavioural intervention for their young child with autism. J Autism Dev Disord. 2001;31:327-36. doi:10. 1023/A:1010799320795.

54. Hastings RP, Kovshoff H, Brown T, Ward NJ, Espinosa FD, Remington B. Coping strategies in mothers and fathers of preschool and school-age children with autism. Autism. 2005;9: 377-91. doi:10.1177/1362361305056078. 
55. Hastings RP, Kovshoff H, Ward NJ, Espinosa FD, Brown T, Remington B. Systems analysis of stress and positive perceptions in mothers and fathers of pre-school children with autism. J Autism Dev Disord. 2005;35:635-44. doi:10.1007/s10803-0050007-8.

56. Higgins DJ, Bailey SR, Pearce JC. Factors associated with functioning style and coping strategies of families with a child with an autism spectrum disorder. Autism. 2005;9:125-37. doi:10.1177/ 1362361305051403.

57. Jones L, Totsika V, Hastings RP, Petalas MA. Gender differences when parenting children with autism spectrum disorders: a multilevel modelling approach. J Autism Dev Disord. 2013;43:2090-8. doi:10.1007/s10803-012-1756-9.

58. Kayfitz AD, Gragg MN, Orr RR. Positive experiences of mothers and fathers of children with autism. J Appl Res Intellect Disabil. 2010;23:337-43. doi:10.1111/j.1468-3148.3009.00539.x.

59. Lee GK. Parents of children with high functioning autism: how well do they cope and adjust? J Dev Phys Disabil. 2009;21:93114. doi:10.1007/s10882-008-9128-2.

60. Little L. Differences in stress and coping for mothers and fathers of children with Asperger's syndrome and nonverbal learning disorders. Pediatr Nurs. 2002;28:565-70.

61. Lyons AM, Leon SC, Phelps CE, Dunleavy AM. The impact of child symptom severity on stress among parents of children with ASD: the moderating role of coping styles. J Child Fam Stud. 2010;19:516-24. doi:10.1007/s10826-009-9323-5.

62. MacMullin J, Tint A, Weiss J. Professional support and positive gain for mothers of children with ASD. J Dev Disabil. 2011;17: 60-3.

63. Mak WW, Ho AH, Law RW. Sense of coherence, parenting attitudes and stress among mothers of children with autism in Hong Kong. J Appl Res Intellect Disabil. 2007;20:157-67. doi:10.1111/ j.1468-3148.2006.00315.x.

64. McStay RL, Dissanayake C, Scheeren A, Koot HM, Begeer S. Parenting stress and autism: the role of age, autism severity, quality of life and problem behaviour of children and adolescents with autism. Autism. 2013;8:1-9. doi:10.1177/1362361313485163.

65. Orr RR, Cameron SJ, Dobson LA, Day DM. Age-related changes in stress experienced by families with a child who has developmental delays. Ment Retard. 1993;31:171-6.

66. Paynter J, Riley E, Beamish W, Davies M, Milford T. The double ABCX model of family adaptation in families of a child with an autism spectrum disorder attending an Australian early intervention service. Res Autism Spectr Disord. 2013;7:1183-95. doi:10. 1016/j.rasd.2013.07.006.

67. Pisula E, Kossakowska Z. Sense of coherence and coping with stress among mothers and fathers of children with autism. J Autism Dev Disord. 2010;40:1485-94. doi:10.1007/s10803-0101001-3.

68. Rivard M, Terroux A, Parent-Boursier C, Mercier C. Determinants of stress in parents of children with autism spectrum disorders. J Autism Dev Disord. 2014. doi:10.1007/s10803-013-2028-x.

69. Rodrigue JR, Morgan SB, Geffken G. Families of autistic children: psychological functioning of mothers. J Clin Psychol. 1990;19:371-9. doi:10.1207/s15374424jccp1904_9.

70. Siman-Tov A, Kaniel S. Stress and personal resource as predictors of the adjustment of parents to autistic children: a multivariate model. J Autism Dev Disord. 2011;41:879-90. doi:10.1007/ s10803-010-1112-x.

71. Tehee E, Honan R, Hevey D. Factors contributing to stress in parents of individuals with autistic spectrum disorders. J Appl Res Intellect Disabil. 2009;22:34-42. doi:10.1111/j.1468-3148. 2008.00437.x.

72. Tobing LE, Glenwick DS. Predictors and moderators of psychological distress in mothers of children with pervasive developmental disorders. J Fam Soc Work. 2007;10:1-22. doi: 10.1300/J039v10n04 01

73. Tomanik S, Harris GE, Hawkins J. The relationship between behaviours exhibited by children with autism and stress. J Intellect Dev Disabil. 2004;29:16-26. doi:10.1080/13668250410001662892.

74. Weiss MJ. Hardiness and social support as predictors of stress in mothers of typical children, children with autism, and children with mental retardation. Autism. 2002;6:115-30. doi:10.1177/ 1362361302006001009 .

75. Zablotsky B, Anderson C, Law P. The association between child autism symptomatology, maternal quality of life, and risk for depression. J Autism Dev Disord. 2012;43:1946-55. doi:10.1007/ s10803-012-1745-z.

76. Anderson DK, Oti RS, Lord C, Welch K. Patterns of growth in adaptive social abilities among children with autism spectrum disorders. J Abnorm Child Psychol. 2009;37:1019-34. doi:10.1007/ s10802-009-9326-0.

77. Baghdadli A, Assouline B, Sonie S, Pernon E, Darrou C, et al. Developmental trajectories of adaptive behaviours from early childhood to adolescence in a cohort of 152 children with Autism Spectrum Disorders. J Autism Dev Disord. 2012;42: 1314-25. doi:10.1007/s10803-011-1357-z.

78. Benson PR, Karlof KL. Anger, stress proliferation, and depressed mood among parents of children with ASD: a longitudinal replication. J Autism Dev Disord. 2009;39:350-63. doi:10.1007/ s10803-008-0632-0.

79. Benson PR, Kersh J. Marital quality and psychological adjustment among mothers of children with ASD: cross-sectional and longitudinal relationships. J Autism Dev Disord. 2011;41:1675-85. doi:10.1007/s10803-011-1198-9.

80. Chadwick O, Cuddy M, Kusel Y, Taylor E. Handicaps and the development of skills between childhood and early adolescence in young people with severe intellectual disabilities. J Intellect Disabil Res. 2005;49:877-88. doi:10.1111/j.1365-2788.2005.00716.x.

81. Gray DE. Ten years on: a longitudinal study of families of children with autism. J Intellect Dev Disabil. 2002;27:215-22. doi:10. 1080/1366825021000008639.

82. Gray K, Keating C, Taffe J, Brereton A, Einfeld S, Tonge B. Trajectory of behaviour and emotional problems in autism. Am J Intellect Dev Disabil. 2012;117:121-33. doi:10.1352/ 1944-7588117-2.121.

83. Herring S, Gray K, Taffe J, Tonge B, Sweeney D, Einfeld S. Behaviour and emotional problems in toddlers with pervasive developmental disorders and developmental delay: associations with parental mental health and family functioning. J Intellect Disabil Res. 2006;50:874-82. doi:10.1111/j.1365-2788.2006.00904.x.

84. Lecavalier L, Leone S, Wiltz J. The impact of behaviour problems on caregiver stress in young people with autism spectrum disorders. J Intellect Disabil Res. 2006;50:172-83. doi:10.1111/j.13652788.2005.00732.x.

85. Lounds J, Seltzer MM, Greenberg JS, Shattuck PT. Transition and change in adolescents and young adults with autism: longitudinal effects on maternal well-being. Am J Ment Retard. 2007;112:401-17.

86. McGovern CW, Sigman M. Continuity and change from early childhood to adolescence in autism. J Child Psychol Psychiatry. 2005;46:401-8. doi:10.1111/j.1469-7610.2004.00361x.

87. Osborne LA, Reed P. The relationship between parenting stress and behaviour problems of children with autism spectrum disorders. Except Child. 2009;76:54-73. doi:10.1542/peds. 2006-2089Q.

88. Peters-Scheffer N, Didden R, Korzilius H. Maternal stress predicted by characteristics of children with autism spectrum disorder and intellectual disability. Res Autism Spectr Disord. 2012;6: 696-706. doi:10.1016/j.rasd.2011.10.003.

89. Pottie CG, Ingram KM. Daily stress, coping, and well-being in parents of children with autism: a multilevel modelling approach. J Fam Psychol. 2008;22:855-64. doi:10.1037/a0013604. 
90. Shattuck PT, Seltzer MM, Greenberg JS, Orsmond GI, Bolt D, Kring $\mathrm{S}$, et al. Change in autism symptoms and maladaptive behaviours in adolescents and adults with autism spectrum disorder. J Autism Dev Disord. 2007;37:1735-47. doi:10.1007/s10803-006-0307-7.

91. Shattuck PT, Wagner M, Narendorf S, Sterzing P, Hensley M. Post-high school service use among young adults with an autism spectrum disorder. Arch Pediatr Adolesc Med. 2011;165:141-6. doi:10.1001/archpediatrics.2010.279.

92. Smith LE, Greenberg JS, Seltzer MM. Social support and wellbeing at mid-life among mothers of adolescents and adults with autism spectrum disorder. J Autism Dev Disord. 2012;42: 1818-26. doi:10.1007/s10803-011-1420-9.

93. Taylor JL, Seltzer MM. Changes in the autism behavioural phenotype during the transition to adulthood. J Autism Dev Disord. 2010;40:1431-46. doi:10.1007/s10803-010-1005-z.

94. Totsika V, Hastings RP, Emerson E, Lancaster GA, Berridge DM, Vagenas D. Is there a bidirectional relationship between maternal wellbeing and child behaviour problems in autism spectrum disorders? Longitudinal analysis of a population-defined sample of young children. Autism Res. 2013;6:201-11. doi:10.1002/aut.1279.
95. Moos RJ, Moos BS. Family environment scale manual. Palo Alto: Consulting Psychologists; 1981.

96. Bristol MM. Family resources and successful adaptation to autistic children. In: Schopler E, Meisbov GB, editors. The effects of autism on the family. New York: Plenum; 1984.

97. Seligman M, Darling RB. Ordinary families, special children: a systems approach to childhood disability. New York: Guilford; 1997.

98. Antonovsky A, Sourani T. Family sense of coherence and family adaptation. J Marriage Fam. 1988;50:79-92.

99. Anderson KH. The relationship between family sense of coherence and family quality of life after illness diagnosis. Collective and consensus views. In: McCubbin HI, Thompson EA, Thompson AI, Fromer JE, editors. Stress, coping, and health in families. Sense of coherence and resiliency. Thousand Oaks: SAGE; 1998.

100. Lustig DC. Families with an adult with mental retardation: predictors of family adjustment. J Appl Rehab Couns. 1999;30:11-8.

101. Perry A. A model of stress in families of children with developmental disabilities: clinical and research applications. J Dev Disabil. 2004;11:1-16. 